\title{
Potencial de logística reversa de pilhas e baterias no Tribunal de Justiça de Pernambuco, Brasil
}

\section{Gizeli Maria da Cunha Accioly ${ }^{\mathbf{1}}$, Luiz Filipe Alves Cordeiro $^{2}$, Aldo Torres Sales ${ }^{2}$, Juliana Gonçalves de Araújo $^{3}$ e Daniele de Castro Pessoa de Melo $^{2}$}

${ }^{1}$ Instituto de Tecnologia de Pernambuco (ITEP). Mestrado Profissional em Tecnologia Ambiental. Avenida Prof. Luís Freire, 700. Cidade Universitária. Recife-PE, Brasil (CEP 50740-540).*E-mail: gizeliacciolycunha@gmail.com.

${ }^{2}$ Instituto de Tecnologia de Pernambuco (ITEP). Av. Prof. Luís Freire, 700. Cidade Universitária, Recife-PE, Brasil (CEP 50740-540).

${ }^{3}$ Universidade de Pernambuco. Av. Gov. Agamenon Magalhães, S/№. Santo Amaro. Recife-PE, Brasil (CEP 50100-010).

Resumo. 0 crescimento das cidades e da população favorece o aumento na geração de resíduos. Dentre esses resíduos, encontram-se as pilhas e baterias, que contêm metais pesados (elementos traços) perigosos, tais como chumbo, cádmio e mercúrio. Quando descartados incorretamente, esses metais contaminam o meio ambiente. Neste contexto, o Brasil adotou a Política Nacional de Resíduos Sólidos, que sugere aos fabricantes de pilhas e baterias implantarem o sistema de Logística Reversa (LR). Em conformidade com as orientações supramencionadas, o Conselho Nacional de Justiça (CNJ) estabeleceu para o Poder Judiciário o Plano de Logística Sustentável (PLS), tendo o presente estudo o objetivo geral de analisar a percepção de risco e de descarte dos servidores do TJPE de pilhas e baterias. Para atingir esse objetivo foi realizada uma análise da rota tecnológica da gestão integrada dos mencionados resíduos sólidos no processo de pós-uso e de possíveis melhorias no TJPE. Além disso, foi realizado um estudo com relação ao grau de conhecimento dos servidores do aludido Tribunal a respeito do descarte e efeitos da não conformidade legal processual. Conclui-se que o TJPE apresenta uma estrutura de LR com uma rota direcionada para reciclagem e que a responsabilidade da LR ainda é desconhecida pelos servidores.

Palavras-chave: Meio ambiente; Resíduos sólidos; Setor público.

Abstract. Reverse logistics potential of batteries in the court of justice of Pernambuco, Brazil. The growth of cities and population favors an increase in waste generation. Among these residues are batteries, which contain dangerous metals heavy (trace elements), such as lead, cadmium and mercury. When discarded incorrectly, these metals contaminate the environment. In this context, Brazil has adopted the National Solid Waste
Recebido

$31 / 07 / 2020$

Aceito

$26 / 08 / 2020$

Disponível on line

$27 / 08 / 2020$

Publicado

$31 / 08 / 2020$

Acesso aberto

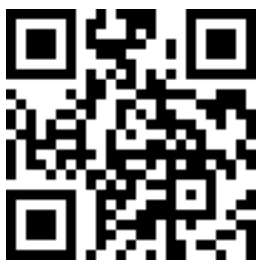

ORCID

(ㄱ) 0000-0003-3015-0838 Gizeli Maria da Cunha Accioly

(D) 0000-0001-8146-9465 Luiz Filipe Alves

Cordeiro

ISSN 2359-1412/RBGAS-2019-0109/2020/7/16/26/855

Rev. Bras. Gest. Amb. Sustent.

http://revista.ecogestaobrasil.net 
Policy, which suggests that battery manufacturers set up the Reverse Logistics (RL) system. In accordance with the aforementioned guidelines, the National Council of Justice (NCJ) established the Sustainable Logistics Plan (SLP) for the Judiciary, the present study having the general objective of analyzing the perception of risk and disposal of TJPE servers of Batteries. To achieve this objective, an analysis of the technological route for the integrated management of the mentioned solid wastes in the post-use process and of possible improvements in the TJPE was carried out. In addition, a study was carried out with respect to the degree of knowledge of the employees of the referred Court regarding the disposal and effects of procedural legal noncompliance. It is concluded that the TJPE has an RL structure with a route directed to recycling and that the responsibility of the RL is still unknown to the employees.

Keywords: Environment; Solid waste; Public sector.
다 $0000-0003-2585-3221$

Aldo Torres Sales

(1) 0000-0003-2677-4357

Juliana Gonçalves de

Araujo

(1) 0000-0003-4058-092X

Daniele de Castro

Pessoa de Melo

\section{Introdução}

A Revolução Industrial trouxe transformações nos costumes da humanidade, com um aumento na produção de bens de consumo que como consequência vem causando desequilíbrio ambiental. 0 modelo de economia que estimulo a um aumento desenfreado no consumo na população tem se se mostrado um modelo insustentável do ponto de vista ambiental (Carvalho et al., 2018). Especialmente dado pela alta quantidade de resíduo gerado. 0 gerenciamento dos resíduos sólidos continua sendo um obstáculo na busca de modelos de convivência mais sustentável com meio ambiente e passa a ser encarado como uma das prioridades por vários governos na busca de alcanças os Objetivos de Desenvolvimento Sustentável da ONU (Abdel-Shafy e Mansour, 2018).

O Conselho Nacional do Meio Ambiente (CONAMA) estabeleceu regras para os resíduos de pilhas e baterias, onde descreve que os mesmos precisam ser devolvidos pelos usuários para que os fabricantes deem o tratamento apropriado, conforme art. $1^{\mathrm{o}}$ da Resolução CONAMA no 257/1999 (Brasil, 1999).

0 art. 2º, da Resolução no 401 (Brasil, 2008) considera baterias como: "acumuladores recarregáveis ou conjuntos de pilhas, interligados em série ou em paralelo". Conforme o art. $3^{\circ}$, $\S 3^{\circ}$, desta mesma resolução, os fabricantes nacionais e importadores de pilhas e baterias devem apresentar o plano de gerenciamento ao órgão ambiental competente para a destinação final correta.

No Brasil, a Green Eletron tem a incumbência de estruturar a Logística Reversa de Equipamentos Eletroeletrônicos, dentre esses, pilhas e baterias. A Associação Brasileira da Indústria Elétrica e Eletrônica (ABINEE) fundou a Green Eletron para buscar soluções a fim de realizar a coleta, o transporte e a reciclagem pós-uso desses resíduos, ajudando na demanda do governo, da sociedade e das empresas (ABINEE S/A), que foi regulamentada através do Decreto no 7.404/2010 (Brasil, 2010). Para tanto, o Estado de Pernambuco, vem avançando com acordos setoriais multi institucionais, buscando a implantação da logística reversa de pilhas e baterias. Assim, foi formalizado um Termo de Compromisso, objetivando implantar um sistema para a destinação final correta dos resíduos de pilhas e baterias em todo o Estado, conforme a Secretaria Estadual do Meio Ambiente e Sustentabilidade (SEMAS) (Pernambuco, 2018).

As pilhas e baterias apresentam como componentes metais pesados e perigosos o mercúrio, chumbo, cobre, níquel, zinco, cádmio e lítio, que são substâncias com potencial 
danoso para o ambiente e à saúde humana quando são fabricadas e descartadas inadequadamente. Estes metais pesados possam ser internalizados na teia trófica, podendo chegar aos níveis superiores por meio da bioacumulação, atingindo os seres que estão no topo da teia que realizem a biomagnificiência, acarretando sérias disfunções na saúde humana, como câncer e degeneração no sistema nervoso central, bem como problemas para outros animais de topo de cadeia (Montone, 2019). A ingestão desses alimentos pelo ser humano poderá provocar doenças degenerativas, como o câncer também pode ocorrer a contaminação do solo, lençóis freáticos e cursos d'água, alcançando, assim, os ecossistemas.

No que se referem aos problemas provocados pós-consumo de pilhas e baterias, políticas públicas vêm sendo formatadas para a prática de gestão da destinação final adequada, conforme a Lei no 12.305/2010 (Brasil, 2010).

A Resolução do Conselho Nacional de Justiça no 201/2015 (Brasil, 2015), no art. 23, determina que o Poder Judiciário deve elaborar um relatório de desempenho, através de Plano de Logística Sustentável (PLS). Neste sentido, surgiu o interesse de investigar a percepção de risco e descarte dos servidores com relação aos resíduos de pilhas e baterias no âmbito do Tribunal de Justiça do Estado de Pernambuco (TJPE), a partir da prática de políticas públicas.

Neste cenário, a estruturação da logística reversa de pilhas e baterias tem foco, visto obrigatoriedade legal, determinante de resolução e conhecimento técnico a respeito do potencial perigo que se configura na destinação incorreta de tais materiais.

O TJPE como órgão público pretende estar utilizando as melhores tecnologias administrativas e gerenciais existentes, buscando assim elevar a eficiência e eficácia de processos internos. Neste sentido, estudar tal processo de segregação de pilhas e baterias poderá auxiliar a melhoria do processo, assim como criar modelo para que seja replicado para outras instituições públicas das diversas esferas.

Com foco nesta temática, o presente estudo busca analisar a percepção de risco e de descarte dos servidores do TJPE dos resíduos de pilhas e baterias, em consonância com o Plano de Logística Sustentável (PLS), a partir de estudo de caso no Tribunal de Justiça de Pernambuco (TJPE), conforme determinação do art. 1ํ, da Resolução do CNJ no 201/2015 (Brasil, 2015). Este estudo pretende ser norteador para a disseminação de boas práticas e elevação da qualidade gerencial das rotas tecnológicas dos resíduos de pilhas e baterias.

\section{Legislação a respeito de pilhas e bateria}

O Brasil passou a ter legislação específica sobre pilhas e baterias que contêm mercúrio, cádmio e chumbo através da Resolução CONAMA no 257/1999 (Brasil, 1999), sendo revogada pela Resolução CONAMA no 401/2008 (Brasil, 2008). Esta Resolução, no art. $2^{\circ}$, inciso IX, preocupa-se com a destinação ambientalmente adequada para reduzir os impactos ao meio ambiente e diz quais procedimentos devem ser adotados para coleta, recebimento, reutilização, reciclagem e tratamento ou disposição final.

0 art. 6º da Resolução CONAMA no 401/2008 (Brasil, 2008) diz ser preciso que os estabelecimentos comerciais ou rede de assistência técnica autorizada, encaminhem as pilhas e baterias mencionadas no art. 1o, para uma destinação ambientalmente adequada, de responsabilidade do fabricante ou importador.

O gerenciamento adequado das baterias usadas está se tornando cada vez mais importante devido ao crescimento exponencial do consumo de baterias, que é impulsionado pelo uso de equipamentos eletrônicos portáteis (Kalmykova et al., 2017).

Descartar as pilhas e baterias diretamente no lixo é bastante perigoso, podendo contaminar o solo e assim, o meio ambiente sai perdendo. É importante fazer o 
gerenciamento desses resíduos, diminuir o consumo e fazer o descarte adequado evitando contaminar o meio ambiente.

O capítulo II da Resolução CONAMA no 401/2008 (Brasil, 2008) trata das pilhas e baterias de pilhas elétricas zinco-manganês e alcalino-manganês, e o art. $7^{0}$ determinou que, a partir de $1^{\text {o }}$ de julho de 2009 :

\footnotetext{
Art. 7ํ As pilhas e baterias do tipo portátil, botão e miniatura que sejam comercializadas, fabricadas no território nacional ou importadas, deverão atender aos seguintes teores máximos dos metais de interesse:

I - conter até $0,0005 \%$ em peso de mercúrio quando for do tipo listado no inciso III do art. $2^{\circ}$ desta resolução;

II - conter até $0,002 \%$ em peso de cádmio quando for do tipo listado no inciso III do art. 2o desta resolução;

III - conter até 2,0\% em peso de mercúrio quando for do tipo listado nos incisos $\mathrm{V}$, VI e VII do art. 2 desta resolução.

IV - conter traços de até $0,1 \%$ em peso de chumbo.
}

Com o estabelecido no art. 7ํㅜ, da Resolução CONAMA no 401/2008 (BRASIL, 2008), tenta-se reduzir a geração dos resíduos através de Produções Mais Limpas quando se estabelece o quantitativo de teores máximos dos metais para os fabricantes de pilhas e baterias, minimizando, dessa forma, os impactos negativos causados ao meio ambiente.

Conforme a Lei de Crimes Ambientais, abandonar os resíduos perigosos no meio ambiente de forma diversa do estabelecido em regulamento ou Lei, é crime e as infrações são claramente definidas, o que foi incluído pela PRNS, Lei no 12.305/2010 (Brasil, 2010).

Segundo Milanez e Buhrs (2009), a Resolução no 401/2008 (Brasil, 2008) se omite quanto à definição de metas quantitativas para a coleta e reciclagem de pilhas e baterias, e uma segunda limitação da Resolução foi não propor nenhuma medida para coibir o contrabando no país de pilhas e baterias.

A Resolução CONAMA no 452/2012 (Brasil, 2012) dispõe sobre os procedimentos de controle da importação de resíduos, em consonância com a Convenção de Basiléia sobre o Controle da Movimentação Transfronteiriça de Resíduos Perigosos e seu Depósito. Vale destacar o contido no art. $3^{\circ}$, que diz:

É proibida a importação dos Resíduos Perigosos - Classe I e de rejeitos, em todo o território nacional, sob qualquer forma e para qualquer fim, conforme determina a Lei no 12.305, de 2 de agosto de 2010 (Brasil, 2010).

O objetivo principal desta Resolução é estabelecer mecanismos para acabar com a importação de resíduos perigosos vindo de países industrializados que não podem ser de responsabilidade de outros países, em consonância com a Convenção de Basiléia, que deu o primeiro passo para reprimir o tráfico ilegal dos resíduos e alcançar os objetivos com a gestão eficaz de tais resíduos. A Resolução CONAMA no 452/2012 (Brasil, 2012) veio suprir a lacuna existe na PNRS.

\section{Coleta seletiva}

Da mesma forma, a Política Nacional de Resíduos Sólidos (PNRS), estabelecida pela Lei no 12.305/2010 (Brasil, 2010), adotou medidas para a preservação do meio ambiente, conforme o art. 8, inciso III, tais como, a coleta seletiva, os institutos da responsabilidade compartilhada pelo ciclo de vida dos produtos, bem como os sistemas de logística reversa. Para Lisboa (2017, p. 13), “a PNRS se insere no âmbito das grandes discussões da atualidade visto que estão previstas ações corretivas para além da disposição final dos 
resíduos, como a redução da geração destes, o incentivo a sua reciclagem, reutilização e reaproveitamento".

Realizando a reciclagem dos resíduos ocorre a redução dos custos para tratamento desses em aterros e atrasa também a geração de lixo (Silvia et al., 2017). Os impactos ambientais podem ser reduzidos e/ou mitigados com os processos de reutilização e de reciclagem dos resíduos sólidos, visto que a incineração pode ser prejudicial para a saúde do homem e o meio ambiente. Desta forma, a reutilização proporciona uma melhor proteção ao meio ambiente (Sandin e Peters, 2018). Da mesma forma, a matéria-prima descartada em aterros e reaproveitada colabora nas gestões de resíduos. Conforme o inciso XVIII, art. 3o, da PNRS "reutilização: processo de aproveitamento dos resíduos sólidos sem sua transformação biológica, física ou físico-química”.

\section{Logística reversa}

A definição de logística reversa encontra-se inserida no art. $3^{\circ}$, inciso XII, da Lei 12.305/2010 (Brasil, 2010) a qual diz que ser:

Instrumento de desenvolvimento econômico e social caracterizado por um conjunto de ações, procedimentos e meios destinados a viabilizar a coleta e a restituição dos resíduos sólidos ao setor empresarial, para reaproveitamento, em seu ciclo ou em outros ciclos produtivos, ou outra destinação final ambientalmente adequada (Brasil, 2010).

Para a PNRS, a logística reversa inversa é o sentido contrário dos fluxos dos produtos depois de consumidos, ou seja, o retorno do produto do fim para o início, para que assim ocorra o reaproveitamento e a destinação final correta. Para que esse processo de devolução do resíduo ao fabricante ocorra, será preciso o envolvimento do consumidor.

No Brasil, a PNRS, visa práticas de gestão para a destinação dos resíduos sólidos como coleta, reciclagem, reutilização e destinação final adequada dos resíduos, incluindo os de pilhas e baterias. No aspecto formal, o art. $6^{\circ}$ da mencionada lei contempla em seus princípios o desenvolvimento sustentável e estabelece diretrizes para o descarte de resíduos, prevendo a responsabilidade compartilhada para todos os cidadãos para que ocorra a cooperação entre o poder público, o setor empresarial e demais segmentos da sociedade, dotando os gestores públicos de um aparato legal, inclusive com a previsão de logística reversa.

A PNRS propõe no art. 33, incisos II e VI, que os fabricantes, importadores, distribuidores e comerciantes de pilhas, baterias e produtos eletroeletrônicos e seus componentes implementam sistemas de logística reversa, para o retorno dos produtos depois de usados pelo consumidor. Os objetivos estabelecidos na Lei no 12.305/2010 (Brasil, 2010) faz prevalecer o interesse coletivo, preconiza a proteção da saúde pública, da qualidade do meio ambiente, e a não geração de resíduos, pela redução e reutilização, além do tratamento correto dos resíduos, assim como a disposição final deste ambientalmente correta.

Com a implantação da Lei no 12.305/2010 (Brasil, 2010), a qual veio com vistas ao gerenciamento ambientalmente adequado dos resíduos sólidos, incluídos os perigosos, almeja-se mudanças dentro do setor público para o tratamento adequado dos Resíduos Sólidos Urbanos (RSU). As pilhas e baterias possuem características de corrosividade, reatividade e toxicidade, e são classificadas conforme a Norma Brasileira ABNT NBR 10004 (ABNT, 2004) como resíduos perigosos. Descartar os resíduos perigosos de pilhas e baterias ou quaisquer substâncias destes, de forma regular ou irregular no lixo, causa a contaminação do meio ambiente, o que é muito perigoso. A disposição final ambientalmente adequada é necessária para evitar riscos à saúde pública e à segurança, visando diminuir os impactos causados ao meio ambiente. 
A Instrução Normativa MPOG no 10/2012, do Ministério do Planejamento, Orçamentário e Gestão Secretaria de Logística e Tecnologia da Informação (Brasil, 2012), estabelece regras para a elaboração dos Planos de Gestão de Logística Sustentável (PLS), que são ferramentas de planejamento de responsabilidade do Ministério do Planejamento, Desenvolvimento e Gestão. Esses planos foram criados através do Decreto no 7.746/2012, art. 16 (Brasil, 2012) que determinaram a elaboração e a implantação do plano pela a Administração Pública Federal direta, autárquica e fundacional, e as empresas estatais dependentes, conforme ato editado pela Secretaria de Gestão do Ministério do Planejamento, Desenvolvimento e Gestão, previsto no Decreto no 9.178/2017 (Brasil, 2017):

I - atualização do inventário de bens e materiais do órgão e identificação de similares de menor impacto ambiental para substituição;

II - práticas de sustentabilidade e de racionalização do uso de materiais e serviços;

III - responsabilidades, metodologia de implantação e avaliação do plano; e

IV - ações de divulgação.

Para os problemas causados ao meio ambiente, devido ao descarte incorreto dos resíduos perigosos de pilhas e baterias depois de consumidos, políticas públicas vêm sendo criadas pelos governos com adoção da logística reversa, conforme Lei $\mathrm{n}^{\mathrm{o}}$ 12.305/2010 (Brasil, 2010).

Recentemente, o Governo Federal estabeleceu, através do Decreto no 10.240/2020 (Brasil, 2020h), normas para reforçar a implantação da logística reversa dos equipamentos eletroeletrônicos de uso doméstico e seus componentes no Brasil.

\section{0 poder judiciário e o plano de logística sustentável}

Através da Portaria CNJ no 32/2017 (Brasil, 2017), foi instituído o Plano de Logística Sustentável (PLS), composto de medidas para se diminuir os impactos provenientes de atividade do judiciário, tendo como público alvo os "magistrados, servidores, estagiários e trabalhadores terceirizados de forma direta e, indiretamente, os tribunais, a comunidade local e toda a sociedade". Estão previstas ações de implantação de gestão de resíduos em papel, plástico, vidros, pilhas e baterias, bem como a capacitação de servidores nas questões de responsabilidade social.

Conforme o art. 1ํ, da Resolução CNJ no 201/2015 (Brasil, 2015), os órgãos do Poder Judiciário Nacional devem criar unidade ou núcleos socioambientais, estabelecer suas competências e inclusive a implantação do PLS do Poder Judiciário (PJ). 0 art. $2^{\circ}$ da Resolução diz que devem ser adotados modelos de gestão organizacional por parte dos órgãos e conselhos do Poder Judiciário na promoção da sustentabilidade ambiental, econômica e social. Importante salientar que no art. $3^{\circ}$, consideram-se para fins desta resolução:
I - visão sistêmica,
II- logística sustentável,
III- critérios de sustentabilidade,
IV- práticas de sustentabilidade,
V- práticas de racionalização,
VI- coleta seletiva,
VII- coleta seletiva solidária,
IX- material de consumo,
X- gestão de documental, 


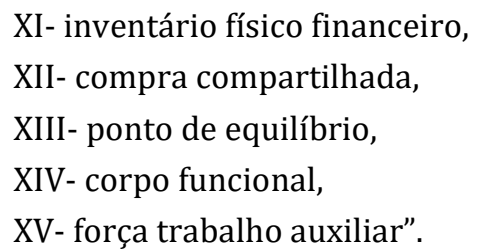

Destacando-se o item VIII - "resíduos recicláveis descartados", como sendo os materiais passiveis de retorno ao seu ciclo produtivo, rejeitados pelos órgãos do Poder Judiciário.

\section{Uma visão do tribunal de justiça de Pernambuco}

O Tribunal de Justiça, como órgão público, enfatiza que adota políticas públicas para diminuir os impactos causados ao meio ambiente em razão de suas atividades rotineiras. Em resposta a esta diretriz, posteriormente, foi criado o Núcleo de Sustentabilidade do TJPE, com competências para promover ações de sustentabilidade e economicidade em suas atividades judicantes. Tal iniciativa está direcionada para a melhoria da eficiência no uso racional de recursos públicos e da qualidade de vida no ambiente de trabalho. Um dos objetivos específicos do Plano de Logística Sustentável (PLS, 2018-2019) do TJPE aduz a gestão de resíduos, encontra-se no item $\mathrm{n}^{-}$6, que busca "Promover a gestão integrada de resíduos pós-consumo, inclusive a destinação ambientalmente correta".

O TJPE apresenta as práticas para alcançar as metas e os resultados que promovem a estabilidade socioambiental através do Relatório de Desempenho do Plano de Logística Sustentável (PLS). Através dos resultados obtidos, podem ser analisados os resíduos de pilhas e baterias da instituição. Neste sentido, o presente trabalho visa analisar o PLS do TJPE em relação às pilhas e baterias.

O PLS de 2016-2018 do TJPE (Pernambuco, 2018, p. 7) diz que o TJPE possui muitos funcionários, e é grande causador de impactos ao meio ambiente. Para atender a determinação contida no Art. 23 da Resolução do CNJ no 201/2015 (Brasil, 2015), a qual refere-se "Ao final de cada ano deverá ser elaborado por cada órgão e conselho do Poder Judiciário relatório de desempenho do PLS-PJ", o TJPE gerou seu relatório de desempenho com os resultados obtidos dos anos de 2016 e 2017 mostrando os resultados alcançados, bem como o avanço do desempenho de indicadores com foco socioambiental e as ações a serem adotadas para o ano subsequente.

\section{Metodologia}

\section{Local de estudo}

O presente estudo foi desenvolvido no TJPE, especificamente no Palácio da Justiça, localizado na Praça da República, sem número, bairro de Santo Antônio, Recife-PE, prédio sede do Tribunal de Justiça do Estado de Pernambuco (TJPE), que foi inaugurado em 7 de setembro de 1930. Nessa área da Praça da República, encontram-se quatro construções históricas: O Teatro Santa Isabel, o Liceu de Artes e Ofícios, o Palácio da Justiça e o Palácio do Governo (Barbosa, 2009).

\section{Passos metodológicos}

Buscando-se atingir os objetivos desta pesquisa, foram realizadas abordagens qualitativa e quantitativa.

Para o estabelecimento da análise quantitativa, foi elaborado um questionário referente ao descarte de resíduos sólidos perigosos de pilhas e baterias e aplicado aos servidores efetivos do TJPE. Esse questionário teve como objetivo identificar a percepção 
de risco e descarte por parte dos servidores a respeito da temática. Para a coleta dos dados, foi utilizado o aplicativo WhatsApp com a finalidade de enviar do questionário referente à temática para 330 servidores do TJPE. Todavia, apenas 157 servidores do mencionado Tribunal responderam ao questionário. Os dados coletados foram essenciais para a análise das informações.

Para discutir a questão qualitativa, buscou-se dados secundários a partir da pesquisa documental. Para a análise do discurso, foram utilizados os dados do PLS do TJPE e do painel de indicadores anuais do CNJ.

\section{Da coleta de dados}

Em princípio, foi elaborado um questionário referente ao descarte de resíduos sólidos perigosos de pilhas e baterias e aplicado aos servidores efetivos do TJPE.

Foi utilizada a plataforma do Google docs para a criação do questionário e, ao final, o programa apresentou os resultados obtidos com as percentagens relativas a cada resposta.

A coleta dos dados ocorreu com a disponibilização de um link que continha um questionário, encaminhado através do aplicativo WhatsApp.

Foram enviados para 330 servidores do TJPE via WhatsApp o questionário acerca da temática "Descarte de pilhas e baterias", com perguntas sobre os riscos do descarte incorreto desses resíduos, bem como se o descarte das pilhas e baterias no lixo comum causaria perigo ao meio ambiente e à saúde dos seres humanos, e também do local onde os servidores descartam suas pilhas e baterias depois de utilizadas. Foi perguntado, ainda, se o servidor tinha conhecimento de alguma lei ou norma que tratasse do descarte dos mencionados resíduos, além de outras questões, contudo, somente responderam ao questionário no período compreendido entre de 22 a 24 de abril de 2020, cento de cinquenta e sete (157) pessoas, todos servidores do TJPE.

A população deste estudo foi constituída por servidores efetivos do TJPE, conforme descrito: com os dados obtidos através da Secretaria de Gestão de Pessoas (SGP) do TJPE, constatou-se que, atualmente, trabalham no Palácio da Justiça do Estado de Pernambuco um total de 359 servidores, compostos por funcionários efetivos. fórmula:

Para o grau de confiança de $90 \%$ e estimativa de erro de $5 \%$. Aplicou-se a seguinte

$$
\begin{aligned}
& \mathrm{N}=359, Z \alpha / 2=1,645, \quad \mathrm{E}=5 \%=0,05 \\
& \mathrm{n}=\frac{0.25 \times 359(1.645)^{2}}{0,25 \times(1,645)^{2}+(359) \cdot(0,05)^{2}} \\
& \mathrm{n}=\frac{242,86}{0,6765}+0,895 \\
& \mathrm{n}=154,54 \\
& \mathrm{n}=155
\end{aligned}
$$

Onde: $\mathrm{n}=$ número da amostra $=157 ; \mathrm{N}=$ número da população $=359 ; \mathrm{Z} \alpha / 2=$ valor crítico equivalente grau de $90 \% ; \mathrm{E}=$ margem de erro $=5 \%=0,05$. Assim, adquirimos o número da amostra de 155. 


\section{Resultados e discussão}

O TJPE, buscando adotar políticas públicas para a preservação do meio ambiente e atender à recomendação do CNJ, editou a Portaria TJPE no 13/2009 (Pernambuco, 2009), na qual o art. $1^{\mathrm{o}}$ instituiu o Programa de Sustentabilidade Legal no âmbito do TJPE e o art. $2^{\circ}$ criou o Comitê Gestor do Programa de Sustentabilidade Legal. Posteriormente, o art. 1응 da Portaria TJPE no 13/2009 (Pernambuco, 2009) foi alterado através da Portaria TJPE no 49/2015 (Pernambuco, 2015), passando a vigorar com a fixação de ações e práticas socioambientais. Foi criada a Comissão Gestora do Plano de Logística Sustentável, a qual visa à implantação e execução do PLS, submetendo-se as proposições ao Comitê de Sustentabilidade Legal.

Em momento seguinte, o TJPE centralizou todas as ações institucionais de criação e implantação dos programas socioambientais para serem coordenadas através da Comissão Gestora do PLS e extinguiu o Comitê Gestor do Programa de Sustentabilidade Legal, conforme art. 1ํㅡ, parágrafo único, da Portaria TJPE no 27/2016 (Pernambuco, 2016).

O TJPE elaborou o PLS 2018-2019 seguindo a sugestão da Resolução CNJ no 201/2015 (Brasil, 2015), composta de 104 indicadores agrupados em 15 temas, estando a gestão de resíduos no item 10 (Pernambuco, 2018, p. 17). Cada um dos 15 temas tem o seu objetivo, os indicadores associados e as ações para se atingir as metas. Por exemplo, para os indicadores "são estabelecidas a descrição da meta de 2018, a linha de base (valor realizado ano anterior) e a quantificação da meta deste ano", podendo não ter como estimar a meta para os indicadores de pilhas e baterias em razão de ser coletado também do usuário externo (da sociedade), conforme o PLS 2018-2019 do TJPE (Pernambuco, 2018, p. 30).

Dentre os objetivos do Plano de Ação do TJPE 2018-2019 (Pernambuco, 2018 p.30) encontram-se o tema Gestão de Resíduos; bem como as metas para o ano de 2018, estando as pilhas e baterias incluídas nesse tema (Tabela 1).

Tabela 1. Plano de Logística Sustentável do TJPE objetivos.

\begin{tabular}{|lccc|}
\hline Tipologia dos Resíduos (Indicadores) & Descrição da Meta & $\begin{array}{c}\text { Linha de } \\
\text { Base 2017 }\end{array}$ & $\begin{array}{c}\text { Meta } \\
\mathbf{2 0 1 8}\end{array}$ \\
\hline Destinação de pilhas e baterias & $100 \%$ do recolhimento & $0 \mathrm{~kg}$ & $\mathrm{~kg}^{*}$ \\
\hline
\end{tabular}

*Não há como estimar em razão de ser coletado também do usuário externo (da sociedade). Fonte: PLS 2018-2019 (Pernambuco, 2018, p. 30).

Observa-se na Tablea 2 que em relação às pilhas e baterias não há parâmetro de base, porque não havia coleta e consequentemente inexiste dados anteriores (imagino que seja por isso), de modo que a meta é destinar adequadamente $100 \%$ das pilhas e baterias recolhidas no período.

Já para o ano de 2019 (Pernambuco, 2018, p. 30), a meta para pilhas e baterias, continua sendo destinar $100 \%$ do que for recolhido, tendo como linha de base, a quantidade recolhida em 2018, ou seja 169,70 kg (Tabela 2). 
Tabela 2. Plano de Logística Sustentável do TJPE objetivos.

\begin{tabular}{|lccc|}
\hline Tipologia dos Resíduos (Indicadores) & Descrição da Meta & $\begin{array}{c}\text { Linha de Base } \\
\mathbf{2 0 1 8}\end{array}$ & $\begin{array}{c}\text { Meta } \\
\mathbf{2 0 1 9}\end{array}$ \\
\hline Destinação de Pilhas e baterias & $100 \%$ do recolhido & $169,70 \mathrm{~kg}$ & $\mathrm{~kg}^{*}$ \\
\hline
\end{tabular}

Não há como estimar em razão de ser coletado também do usuário externo (da sociedade). Fonte: PLS 2018 - 2019 (Pernambuco, 2018, p. 30).

O Plano de Ação do TJPE de 2018-2019 previu no subitem 7.10.2 a ampliação de pontos de coleta de pilhas para mais um prédio, com prazo de início para o mês de agosto e prazo final para setembro, com a participação da Administração dos Prédios, sob a responsabilidade do Núcleo de Sustentabilidade (NUCS), conforme o PLS 2018-2019 do TJPE, o que de fato ocorreu (Pernambuco, 2018, p. 30 e 31). Observando a Tabela 3, constata-se que, no período de 12 meses, foram descartados ou coletados um total de $169,70 \mathrm{~kg}$ de pilhas e baterias na linha de base de 2018, indicando que havia uma demanda reprimida e que a disponibilização de coletores foi bem recebida pelos usuários que aderiram ao projeto.

A necessidade da gestão ambiental correta para os resíduos é advertida por muitos estudiosos dessa temática (Gui et al., 2019). A conscientização das pessoas sobre a importância de preservar o meio ambiente é fundamental para o sucesso de ações como esta.

Conforme informações do Núcleo de Sustentabilidade (NUCS) do TJPE para esta pesquisa foram realizadas ações de educação ambiental com os servidores do TJPE, tendo uma delas ocorrido em junho de 2017, na Semana do Meio Ambiente, em parceria com o Ecos de Pernambuco. Este grupo é formado por gestores do TJPE, bem como de outros Tribunais, tais como: Tribunal de Contas do Estado de Pernambuco (TCE), Tribunal Regional do Trabalho da 6a Região (TRT6), Tribunal Regional Eleitoral de Pernambuco (TER), Tribunal Regional Federal da $5^{a}$ Região (TRF5) e Universidade Federal Rural de Pernambuco (UFRPE).

A boa aceitação dos usuários estimulou a administração do TJPE a disponibilizar novos locais de coleta de pilhas e baterias, perfazendo hoje um total de treze (13) pontos para descarte desse tipo de resíduo. Os coletores de pilhas e baterias utilizados pelo TJPE são confeccionados com o material acetato de polivinilo (PVC), que é bastante resistente, garantindo durabilidade e adequado acondicionamento dos resíduos até que recebam a destinação correta. Observou-se, também, que os coletores de pilhas instalados no hall de entrada do prédio do Palácio da Justiça do TJPE, são identificados com o logotipo próprio. Na parede acima do coletor, encontra-se um cartaz de conscientização com o seguinte dizer: "Não contamine o meio ambiente, descarte pilhas no local correto".

As ações desenvolvidas no TJPE relativas à destinação correta de pilhas e baterias seguem uma tendência mundial devido à existência de legislações ambientais em muitos países para esse tipo de destinação. Pressões políticas também fazem com que as indústrias recolham suas pilhas e baterias depois de usadas, conforme (Afonso et al., 2003).

Comparando as ações do TJPE com as de outros tribunais estaduais de médio porte, foram obtidos os seguintes dados, a partir do painel do CNJ sobre o Plano de Logística Sustentável do Poder Judiciário PLS-PJ (Brasil, 2018). Para uma melhor compreensão, os dados informados ao CNJ pelos Tribunais de Justiça Estaduais de médio porte quanto à destinação de pilhas e baterias recolhidas em suas dependências, foram colocados em ordem crescente. 
Assim, no ano de 2018, tem-se o Tribunal de Justiça de Santa Catarina (TJSC) com $6.439 \mathrm{~kg}$; o Tribunal de Justiça da Bahia (TJBA) com $1.300 \mathrm{~kg}$; o Tribunal Justiça do Maranhão (TJMA) com $202 \mathrm{~kg}$; o Tribunal de Justiça do Pará (TJPA) com 174 kg; o Tribunal de Justiça de Pernambuco (TJPE) com $170 \mathrm{~kg}$; e o Tribunal de Justiça de Mato Grosso (TJMT) com 148 kg. Observou-se que, dentre os seis Tribunais de Justiça Estaduais de médio porte que recolheram pilhas e baterias no ano de 2018, o TJPE ficou na quinta maior posição de recolhimento de resíduos (Figura 2).

Observou-se que, no ano de 2019, o TJPE continuou na quinta posição em relação aos oitos Tribunais Estaduais de médio porte que informaram ao CNJ a destinação de pilhas e baterias, tendo o TJPE recolhido $326 \mathrm{~kg}$ desses resíduos. Constatou-se, também, que ficou mantida a primeira posição para o Tribunal de Justiça de Santa Catariana (TJSC), com o recolhimento de $8.356 \mathrm{~kg}$ desses resíduos, conforme painel de indicadores anuais do CNJ no relatório do ano de 2019 (Brasil, 2019) (Figura 2).

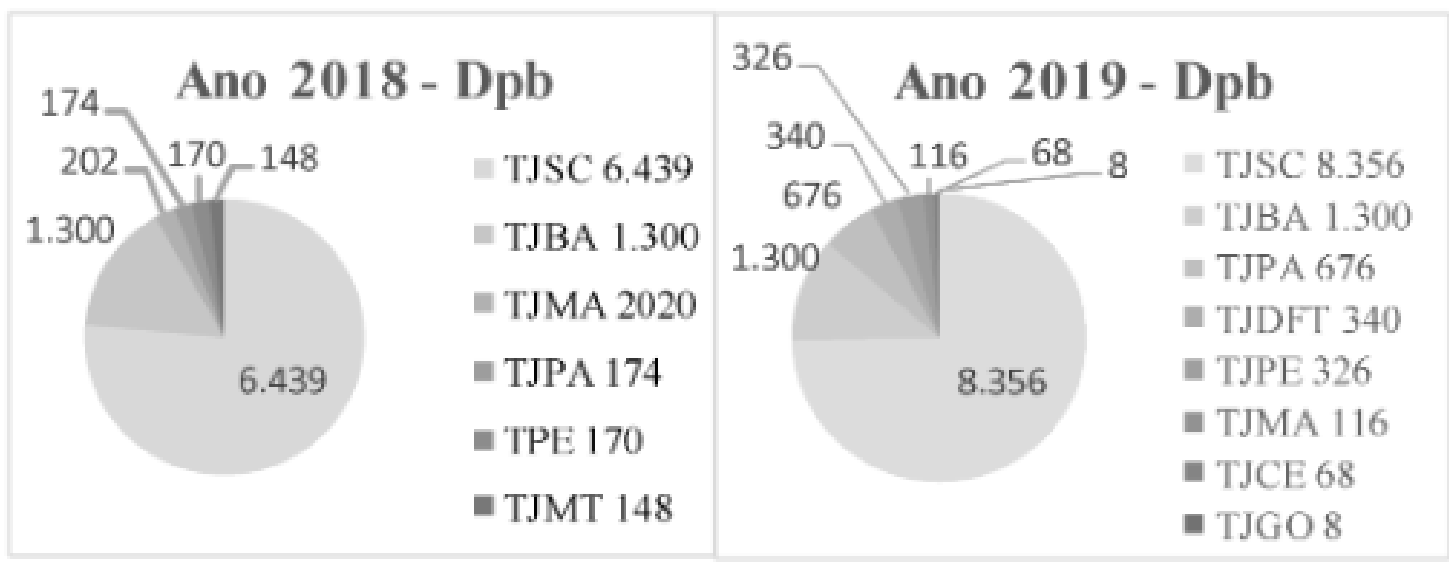

Figura 2. Justiça Estadual - Ano de 2018 e 2019. Dpb - Destinação pilhas e baterias. Fonte: Dados do Painel CNJ do PLS do Poder Judiciário (Brasil, 2018, 2019).

É importante destacar que o TJPE teve um crescimento elevado na quantidade de pilhas e baterias recolhidas para destinação, passando de $170 \mathrm{~kg}$ no ano de 2018 para $326 \mathrm{~kg}$ em 2019, um incremento de mais de $100 \%$.

A ação estabelecida no PLS de 2018-2019 de aumentar o número de coletores de pilhas e baterias no TJPE para o ano de 2019 contribuiu para um aumento significativo da quantidade de resíduos recolhidos em 2019, conforme o PLS de 2018-2019 do TJPE (Pernambuco, 2018, p. 30).

0 estabelecimento de rotas tecnológicas que estejam na conformidade com a legislação é um grande desafio existente para o descarte dos resíduos de pilhas e baterias (Aguiar e El-Deir, 2019). A implantação da coleta seletiva e a operacionalização da logística reversa de pilhas e baterias fazem com que a rota tecnológica oportunize estes materiais para um novo ciclo produtivo.

Vale mencionar que foi realizada campanha nas redes sociais do TJPE, através de site, intranet e TV indoor \#Consumo Consciente, pela Assessoria de Comunicação, mostrando dicas de sustentabilidade de muitas temáticas, inclusive a Gestão de Resíduos com o objetivo de aumentar a destinação ambientalmente correta dos resíduos produzidos nas unidades de trabalho. Com esta ação de aumentar o número de pontos de coleta para mais prédios, assim como a realização de campanhas nas redes sociais com 
dicas de sustentabilidade e de Gestão de Resíduos, o TJPE mostrou que houve uma estrutura de coleta seletiva, bem como existiu uma maior participação dos servidores aderindo a este procedimento.

A rota tecnológica dos resíduos sólidos de pilhas e baterias coletados internamente pelo TJPE, conforme dados fornecidos pelo NUCS, inicia-se com a equipe da Administração dos prédios, que recolhe dos coletores e armazena em bombonas seguras e fechadas as pilhas e baterias descartadas, sendo o ponto de coleta primário. Em seguida, esses resíduos são encaminhados para o ponto de coleta secundário, que é a instituição parceira Sindicato do Comércio Varejista de Gêneros Alimentícios do Recife (SINDVAREJISTA), pertencente ao Programa Papão de Pilhas, o qual foi criado para atender à Resolução CONAMA no 401/2008 (Brasil, 2008). Depois desse ponto, a Green Eletron é a operadora responsável no Estado de Pernambuco pelo recolhimento e logística do transporte das pilhas e baterias portáteis e dá uma destinação final adequada, nos termos dos normativos pertinentes.

De acordo com a Secretaria Estadual do Meio Ambiente e Sustentabilidade (Semas), para a implantação da logística reversa de pilhas e baterias portáteis, o Estado de Pernambuco formalizou um Termo de Compromisso que tem como objetivo adotar medidas em todas as regiões do Estado, visando implantar um sistema para a destinação correta desses resíduos (Pernambuco, 2018).

O NUCS também mencionou, para fins desta pesquisa, que o TJPE recebeu parecer jurídico favorável à assinatura do Termo de Adesão ao Programa Papão de Pilhas, e que seguirá orientações, no que couber, do Termo de Compromisso supramencionado. Relatou, ainda, que o SINDIVAREJISTA, entidade que recebe diretamente os resíduos descartados em seus coletores, elabora e fornece certificado para o TJPE pelo encaminhamento desses resíduos perigosos. Ademais, o NUCS informou que os resíduos das pilhas e baterias do TJPE retornam aos fabricantes e importadores através da Green Eltron.

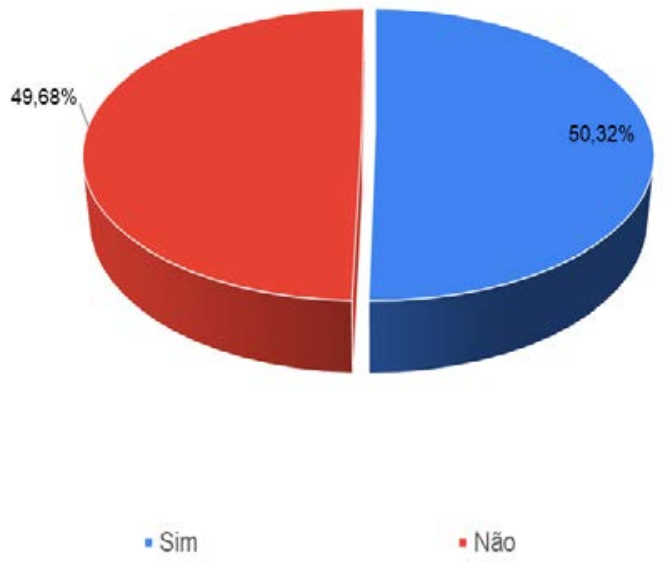

Figura 3. Conheci lei ou norma de descarte de pilhas/baterias.

\section{Análise geral dos dados}

Quando questionado aos servidores se tinham conhecimento de alguma lei ou norma que tratasse do descarte correto de pilhas e baterias, constatou-se que $50,32 \%$ dos 
entrevistados afirmaram conhecer e a outra metade não conheciam $(49,68 \%)$. Um fato que chamou atenção nos resultados encontrados foi que praticamente possuem os mesmos números de respostas sim e não, percebendo-se com isso que o assunto é pouco conhecido pelos servidores (Figura 3).

A pesquisa também apresentou uma correlação de 31,30\% entre as variáveis "conhecimento de alguma lei ou norma específica que trate do descarte correto de pilhas e baterias" versus "a variável onde descartam suas pilhas e baterias utilizadas".

Levando-se em consideração que um dos objetivos específicos estabelecido pelo PLS do TJPE 2018-2019 (Pernambuco, 2018 p. 10) é "contribuir para implementação da cultura da sustentabilidade, mediante praticas educativas", ficou evidente com esses resultados que os objetivos específicos estabelecidos pelo PLS não foram alcançados.

Perguntando aos servidores do TJPE onde descartam suas pilhas e baterias pósconsumo, a grande maioria dos entrevistados $(75,80 \%)$ responderam que descartam nos coletores apropriados, entretanto, $22,29 \%$ descartam no lixo comum. Este descarte de pilhas e baterias no lixo comum está em desacordo com os preceitos legais e técnicos (Figura 4).

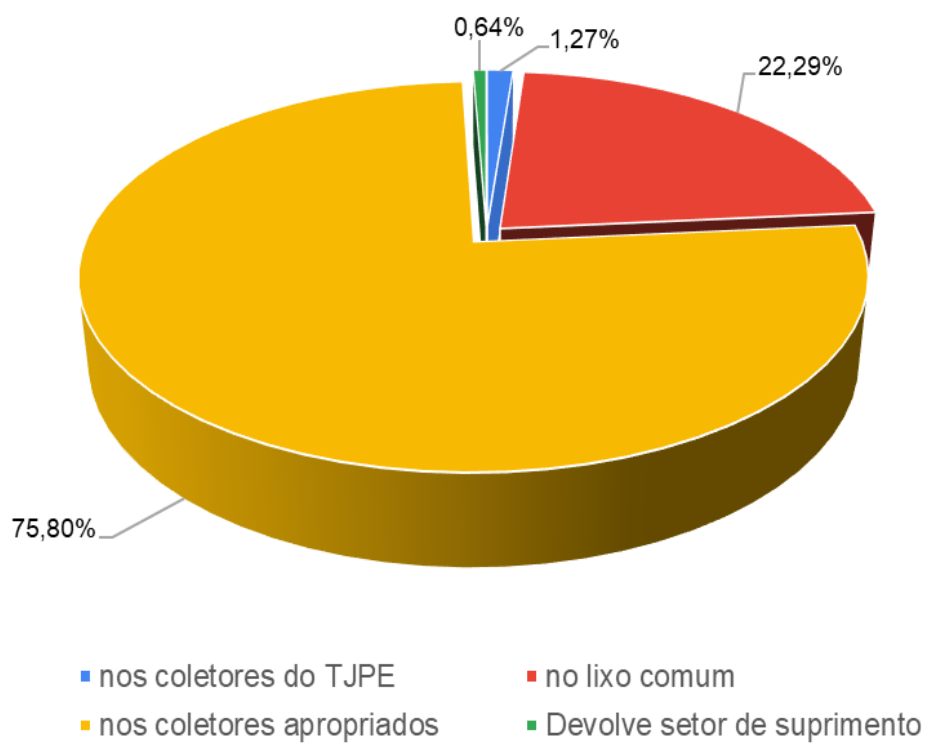

Figura 4. Onde descartar pilhas e baterias.

Para Afonso et al. (2003), as pilhas durante muitas décadas foram jogadas diretamente no lixo comum devido ao desconhecimento coletivo ambiental. Um fato grave é o descarte diretamente no lixo comum desses resíduos perigosos, o que provoca a contaminação do meio ambiente e é prejudicial para a saúde humana, devido aos metais pesados perigosos existentes em sua composição como o mercúrio, chumbo e cádmio. Diante disso, os órgãos públicos necessitam estimular seus servidores a terem mudanças comportamentais e passem a utilizar nas rotinas de trabalho critérios de gestão socioambiental. A Agenda Ambiental da Administração Pública (A3P), definida no programa do Ministério do Meio Ambiente (MMA), visa estimular os órgãos públicos, a implementarem princípios e critérios de gestão para a sustentabilidade, bem como a gestão adequada dos resíduos (Brasil, 2009, p. 30). 
Com o resultado da pesquisa, verificou-se que apenas uma pequena minoria $(1,27 \%)$ dos servidores utilizam os coletores do TJPE ou $0,64 \%$ devolve para o setor de suprimento.

A pesquisa apontou ainda uma correlação de 28,33\% entre as variáveis "onde descarta suas pilhas/baterias depois de utilizadas" versus "já utilizou algum coletor de pilhas/baterias do Palácio da Justiça".

Através da questão se os servidores já haviam utilizado algum coletor de pilhas e baterias do Palácio da Justiça, ficou evidente pelos resultados que é grande o número de servidores $(63,69 \%)$ que não utilizam os coletores do Palácio da Justiça, sendo preciso incentivá-los a terem mudanças de hábitos e adotarem critérios de gestão socioambiental nas suas rotinas de trabalho e passem a descartar as pilhas e baterias nos coletores do Palácio da Justiça colaborando com a gestão dos resíduos (Figura 4).

A pesquisa apontou uma correlação de $57 \%$ entre as variáveis "tem conhecimento de que existe coletor de pilhas/baterias no Palácio da Justiça" versus "já utilizou algum coletor de pilhas/baterias do Palácio da Justiça".

A relação de "ter conhecimento da existência de coletor de pilhas e baterias no Palácio da Justiça" versus "já ter utilizado algum coletor de pilhas e baterias do Palácio da Justiça" é importante, pois se comprova com os dados que são poucos os servidores do TJPE que utilizam esses coletores $(63,69 \%)$.

Considerando, ainda, que um dos objetivos específicos do PLS do TJPE 2018-2019 (Pernambuco, 2018, p. 10) é "Promover a gestão integrada de resíduos pós-consumo, inclusive a destinação ambientalmente correta", entende-se que a realização de ações de capacitação é imprescindível para incentivar os servidores a adotarem em suas rotinas de trabalho o senso de corresponsabilidade para a gestão socioambiental.

Com a implantação da PNRS (Brasil, 2010), espera-se mudanças no setor público para a destinação final adequada dos resíduos. Os processos de reutilização e de reciclagem podem diminuir os impactos causados ao meio ambiente, tendo em vista que a incineração pode ser prejudicial para o homem e para o ambiente. Sendo assim, a reutilização resolve um dos grandes problemas ambientais (Sandin e Peters, 2018).

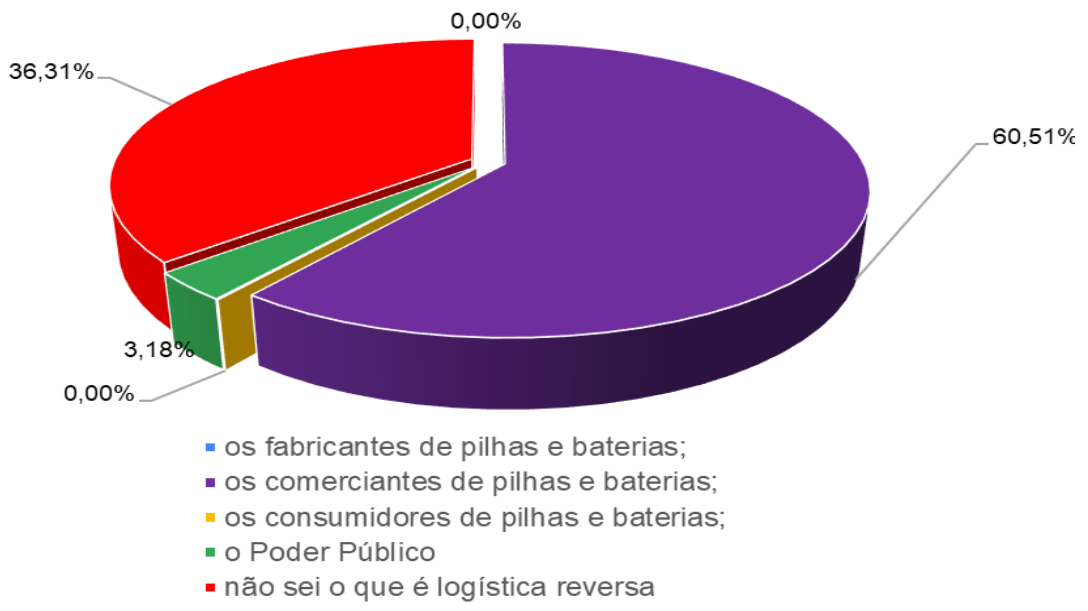

Figura 5. Responsável pela logística reversa.

Quando questionado de quem é a responsabilidade pela logística reversa de pilhas e baterias, $60,51 \%$ servidores entrevistados responderam que era responsabilidade dos 
comerciantes, 36,31\% disseram que não sabiam o que é logística reversa, e 3,18\% acham ser do Poder Público (Figura 5). Contudo, percebeu-se com os resultados encontrados que nenhum dos servidores do TJPE tem o conhecimento do responsável pela logística. 0 que é bastante preocupante essa falta de conhecimento. Sendo assim, é preciso desenvolver um trabalho de educação com os servidores, levando o conhecimento e estimulando-os para atingir a diminuição da geração de resíduos, bem como realizar a destinação ambientalmente correta.

Conforme mencionado no decorrer deste trabalho, a responsabilidade dos comerciantes e empresas revendedoras das pilhas e baterias é apenas do recolhimento e devolução para os fabricantes, ficando a estes e aos importadores a incumbência de dar a destinação ambientalmente adequada para esses produtos, nos termos do Art. 33, parágrafo 6으, da Lei no 12.305/2010 (Brasil, 2010).

Portanto, o TJPE, implantou o PLS, o qual possui procedimentos para alcançar o correto manejo dos resíduos das pilhas e baterias pós-consumo, todavia isso evidencia a ausência de conhecimento por parte dos servidores do responsável pela logística reversa, e demonstra que há necessidade de se ampliar as ações de capacitação. Desse modo, a melhor estratégia é a educação ambiental para os servidores, o que é imprescindível. Finalmente, esta pesquisa permite concluir que formar servidores conscientes e que passem a ter atitudes direcionadas para o bem da natureza, que é de uso comum da humanidade, vai contribuir para a logística reversa do TJPE.

\section{Discussão}

Observou-se que o TJPE tem realizado ações que buscam contribuir para a efetividade do programa de logística reversa de pilhas e baterias no TJPE, uma vez que possui uma estrutura de coleta seletiva.

Constatou-se um número significativo de servidores (22,29\%) que descartam esses resíduos perigosos de forma incorreta, no lixo comum, sem se preocupar com o meio ambiente. Esta observação pode em parte ser associada ao fato de que praticamente metade dos servidores que responderam ao questionário $(49,68 \%)$ não ter conhecimento de lei ou de norma que trate do descarte correto de pilhas e baterias, bem como foi encontrado um número bastante significativo de servidores $(63,69 \%)$ que expressaram não utilizar os coletores de pilhas e baterias da instituição.

A importância da logística reversa de pilhas e baterias ainda é desconhecida por parte dos entrevistados. Portanto se faz necessária um programa de educação ambiental a fim de estimular nos servidores do TJPE um repensarem em seus hábitos, com o propósito de passarem a utilizar nas rotinas de trabalho critérios que contribuam para uma positiva gestão socioambiental.

\section{Conflito de interesses}

Os autores declaram não haver conflito de interesses.

\section{Referências}

Abdel-Shafy, H. I.; Mansour, M. S. Solid waste issue: Sources, composition, disposal, recycling, and valorization. Egyptian Journal of Petroleum, v. 27, n. 4, p. 1275-1290, 2018. https://doi.org/10.1016/j.ejpe.2018.07.003

Afonso, J. C.; Barandas. A. P. M. G.; Silva, G. A. P.; Fonseca, S. G. Processing of the spent battery electrolytes. Química Nova, v. 26, n. 4, p.573-577, 2003. https://doi.org/10.1590/S0100-40422003000400022 
Aguiar, A. C.; El-Deir, S. G. Modelos de gerenciamento de resíduos sólidos: proposta para melhora contínua. In: Nunes, I. L. S.; Pessoa, L. A.; El-Deir, S. G. Resíduos sólidos: os desafios da gestão. 1. ed. Recife: EDUFRPE, 2019.

ABINEE - Associação Brasileira da Indústria Elétrica e Eletrônica. A indústria elétrica e eletrônica impulsionando a economia verde e a sustentabilidade. 2017. Disponível em: <http://www.abinee.org.br/programas/imagens/abinee20.pdf>. Acesso em: 11 jan. 2020.

ABINEE - Associação Brasileira da Indústria Elétrica e Eletrônica. Descarte green. Cartilha informativa. Disponível em: <https://www.greeneletron.org.br/download/CARTILHA_ PILHAS_DIDÁTICA_ILUSTRADA.pdf>. Acesso em: 11 jan. 2020.

ABINEE - Associação Brasileira da Indústria Elétrica e Eletrônica. Logística reversa de pilhas e baterias portáteis. Cartilha de orientações técnicas. Disponível em: <https://www.greeneletron.org.br/descarte.php>. Acesso em: 11 jan. 2020.

ABNT - Associação Brasileira de Normas Técnicas. ABNT NBR no 10004: Resíduos sólidos - classificação. Rio de Janeiro: ABNT, 2004.

Barbosa, V. Palácio da Justiça (Recife, PE). Fundação Joaquim Nabuco, Recife-PE. Disponível em: <http://basilio.fundaj.gov.br/pesquisaescolar/index.php?option= com_content\&id=612>. Acesso em: 8 jun. 2019.

Brasil. Conselho Nacional de Justiça. Plano de Logística Sustentável do Poder Judiciário (PLS-PJ). TJ - Pernambuco - Ano de 2018, Disponível em: <https://paineis.cnj.jus.br/ QvAJAXZfc/opendoc.htm?document=qvw_l\%5Cpainelcnj.qvw\&host=QVS\%40neodimio03 \&anonymous=true\&sheet=shPLSResumo $>$. Acesso em: 10 abr. 2020.

Brasil. Decreto no 10.240, de 12 de fevereiro de 2020. Regulamenta o inciso VI do caput do art. 33 e o art. 56 da Lei no 12.305, de 2 de agosto de 2010, e complementa o Decreto no 9.177, de 23 de outubro de 2017, quanto à implementação de sistema de logística reversa de produtos eletroeletrônicos e seus componentes de uso doméstico. Disponível em: <http://www.planalto.gov.br/ccivil_03/_ato2019-2022/2020/decreto/D10240.htm>.

Acesso em: 15 abr. 2020.

Brasil. Decreto no 7.404 de 23 de dezembro de 2010. Regulamenta a lei no 12.305 , de 2 de agosto de 2010. Institui a política nacional de resíduos sólidos, cria o comitê interministerial da política nacional de resíduos sólidos e o comitê orientador para a implantação dos sistemas de logística reversa. Disponível em: <http://www.planalto.gov.br/ccivil_03/_ato2007-2010/2010/decreto/d7404.htm>.

Acesso em: 14 jan. 2020.

Brasil. Decreto no 7.746, de 5 de junho de 2012. Regulamenta o art. 3을 da Lei no 8.666, de 21 de junho de 1993, para estabelecer critérios, práticas e diretrizes para a promoção do desenvolvimento nacional sustentável nas contratações realizadas pela administração pública federal, e institui a Comissão Interministerial de Sustentabilidade na Administração Pública - CISAP. Disponível em: <http://www.planalto.gov.br/ ccivil_03/_ato2011-2014/2012/decreto/d7746.htm>. Acesso em: 16 abr. 2020.

Brasil. Decreto no 9.178, de 23 de outubro de 2017. Altera o Decreto no 7.746, de 5 de junho de 2012, que regulamenta o art. 3o da Lei no 8.666, de 21 de junho de 1993, para estabelecer critérios, práticas e diretrizes para a promoção do desenvolvimento nacional sustentável nas contratações realizadas pela administração pública federal direta, autárquica e fundacional e pelas empresas estatais dependentes, e institui a Comissão Interministerial de Sustentabilidade na Administração Pública - CISAP. Disponível em: <http://www.planalto.gov.br/ccivil_03/_Ato2015-2018/2017/Decreto/D9178.htm>.

Acesso em: 16 abr. 2020. 
Brasil. Instrução Normativa MPOG no 10, de 10 de novembro de 2012. Estabelece regras para elaboração dos Planos de Gestão de Logística Sustentável de que trata o art. 16, do Decreto no 7.746, de 5 de junho de 2012, e dá outras providências. Disponível em: <http://www.lex.com.br/legis_23960118_INSTRUCAO_NORMATIVA_N_10_DE_12_>. Acesso em: 16 abr. 2020.

Brasil. Lei no 12.305, de 2 de agosto de 2010. Instituiu a Política Nacional de Resíduos Sólidos; altera a Lei no 9.605, de 12 de fevereiro de 1998; e dá outras providências. Disponível em: <http://www.planalto.gov.br/ccivil03/Ato 2007-2010/2010/Lei/ 112305.htm>. Acesso em: 08 de jan. 2020.

Brasil. Ministério do Meio Ambiente. Como implantar a A3P. 3. ed. Brasília: MMA, 2009. Disponível em: <https://www.mma.gov.br/images/arquivo/80063/Cartilha Intermediaria - Como Implantar a A3P - 03 edicao.pdf>. Acesso em: 07 maio 2020.

Brasil. Resolução CNJ no 201, de 3 de março de 2015. Disponível em: <https://atos.cnj.jus.br/atos/detalhar/2126>. Acesso em 10 abr. 2020.

Brasil. Portaria CNJ no 32, de 23 de maio de 2017. Disponível em: $<$ https://atos.cnj.jus.br/atos/detalhar/atos-normativos?documento=2421>. Acesso em: 16 abr. 2020.

Brasil. Resolução CONAMA no 001, de 17 de fevereiro de 1986. Dispõe sobre critérios básicos e diretrizes gerais para a avaliação de impacto ambiental. Disponível em: <http://www2.mma.gov.br/port/conama/legislacao/CONAMA_RES_CONS_1986_001.pdf> . Acesso em: 07 maio 2020.

Brasil. Resolução CONAMA no 257, de 30 de junho de 1999. Estabelece a obrigatoriedade de procedimentos de reutilização, reciclagem, tratamento ou disposição final ambientalmente adequada para pilhas e baterias que contenham em suas composições chumbo, cádmio, mercúrio e seus compostos. Disponível em: <https://www.mma.gov.br/estruturas/a3p/_arquivos/36_09102008040356.pdf>. Acesso em: 07 maio 2020.

Brasil. Resolução CONAMA no 401, de 4 de novembro de 2008. Estabelece os limites máximos de chumbo, cádmio e mercúrio para pilhas e baterias comercializadas no território nacional e os critérios e padrões para o seu gerenciamento ambientalmente adequado, e dá outras providências. Disponível em: <http://www2.mma.gov.br/port/ conama/legiabre.cfm?codlegi=589>. Acesso em: 07 maio 2020.

Brasil. Resolução CONAMA no 452, de 2 julho de 2012. Dispõe sobre os procedimentos de controle da importação de resíduos, conforme as normas adotadas pela Convenção da Basiléia sobre o Controle de Movimentos Transfronteiriços de Resíduos Perigosos e seu Depósito. Disponível em: <http://www2.mma.gov.br/port/conama/legiabre.cfm? codlegi=676>. Acesso em: 07 maio 2020.

Carvalho, N.; Chaim, O.; Cazarini, E.; Gerolamo, M. Manufacturing in the fourth industrial revolution: A positive prospect in sustainable manufacturing. Procedia Manufacturing, v. 21, p. 671-678, 2018. https://doi.org/10.1016/j.promfg.2018.02.170

Gui, S.; Zhao, L.; Zhang, Z. Does municipal solid waste generation in China support the Environmental Kuznets Curve? New evidence from spatial linkage analysis. Waste Management, v. 84, p. 310-319, 2019. https://doi.org/10.1016/j.wasman.2018.12.006 
Kalmykova, Y.; Berga, P. E.-O.; Patrício, J.; Lisovskaja, V. Portable battery lifespans and new estimation method for battery collection rate based on a lifespan modeling approach. Resources, Conservation and Recycling, v. 120, p.65-74, 2017. https://doi.org/ 10.1016/j.resconrec.2017.01.006

Lisboa, R. Manejo dos resíduos sólidos em Ituiutaba-MG: perspectivas e soluções. Ituiutaba: Universidade Federal de Uberlândia, 2017. (Dissertação de mestrado).

Milanez, B.; Buhrs, T. Capacidade ambiental e emulação de políticas públicas: o caso da responsabilidade pós-consumo para resíduos de pilhas e baterias no Brasil. Rio de Janeiro: IPEA, 2009. Disponível em: <http://www.ipea.gov.br/ppp/index.php/PPP/article/view/ 161/177>. Acesso em: 26 dez. 2019.

Montone, R. C. Bioacumulação e biomagnificação. Brasília: Instituto Oceanográfico, 2019.

Pernambuco. Secretaria do Meio Ambiente e Sustentabilidade. Pernambuco implanta logística reversa de pilhas e baterias portáteis. Disponível em: <http://www2.semas.pe.gov.br/web/semas/exibir_noticia?groupId=709017\&articleId=4 3767049\&templateId=2386863 > . Acesso em: 09 abr 2019.

Pernambuco. Tribunal de Justiça. Relatório de Desempenho do PLS-PJE 2018-2019. Recife: TJPE, 2018.

Pernambuco. Portaria TJPE no 13, de 13 de fevereiro de 2009. Institui o Programa de Sustentabilidade Legal de que trata a Recomendação no 11, de 27 de maio de 2007, do Conselho Nacional de Justiça - CNJ, e cria o Comitê Gestor do Programa de Sustentabilidade Legal, no âmbito do Poder Judiciário do Estado de Pernambuco, e dá outras providências.

Pernambuco. Portaria TJPE no 27, de 09 maio de 2016. Promove a unificação dos grupos de trabalho e dos programas socioambientais do Poder Judiciário de Pernambuco.

Pernambuco. Portaria TJPE no 49, de 06 de agosto de 2015. Institui a Comissão Gestora do Plano de Logística Sustentável (PLS-PJ) no âmbito do Poder Judiciário do Estado de Pernambuco e dá outras providências.

Pernambuco. Plano de logística sustentável do Poder Judiciário do Estado de Pernambuco, 2016-2018. Recife: TJPE, 2018.

Pernambuco. Plano de logística sustentável do Poder Judiciário do Estado de Pernambuco, 2018-2019. Recife: TJPE, 2018.

Sandin, G.; Peters, G. M. Environmental impact of textile reuse and recycling: A review. Journal of Cleaner Production, v. 184, p.353-365, 2018. https://doi.org/10.1016/ j.jclepro.2018.02.266

Silvia, L. M. S.; Paraiso, L. A.; Pinto Junior, M. I. Análise crítica política nacional de resíduos sólidos: principais pontos e aplicabilidade. Ciências Exatas e Tecnológicas, v. 4, n. 2, p. 37-48, 2017.

Informação da Licença: Este é um artigo Open Access distribuído sob os termos da Licença Creative Commons Attribution, que permite uso irrestrito, distribuição e reprodução em qualquer meio, desde que a obra original seja devidamente citada. 